\title{
Solid-State Conformational Flexibility at Work: Energetic Landscape of a Single Crystal-to-Single Crystal Transformation in a Cyclic Hexapeptoid
}

\author{
Giovanni Pierri, Marta Corno, Eleonora Macedi, Maria Voccia, and Consiglia Tedesco*
}

Cite This: Cryst. Growth Des. 2021, 21, 897-907

Read Online

ACCESS

Wlll Metrics \& More

回 Article Recommendations

Supporting Information

ABSTRACT: We describe the energetic landscape beyond the solidstate dynamic behavior of a cyclic hexapeptoid decorated with four propargyl and two methoxyethyl side chains, namely, cyclo-(Nme$\left.\mathrm{Npa}_{2}\right)_{2}, \mathrm{Nme}=\mathrm{N}$-(methoxyethyl)glycine, $\mathrm{Npa}=\mathrm{N}$-(propargyl)glycine . By increasing the temperature above $40{ }^{\circ} \mathrm{C}$, the acetonitrile solvate form 1A starts to release acetonitrile molecules and undergoes a reversible single crystal-to-single crystal transformation into crystal form $1 \mathrm{~B}$ with a remarkable conformational change in the macrocycle: two propargyl side chains move by $113^{\circ}$ to form an unprecedented " $\mathrm{CH}-\pi$ zipper". Then, upon acetonitrile adsorption, the " $\mathrm{CH}-\pi$ zipper" opens and the crystal form 1B transforms back to 1A. By conformational energy and lattice energy calculations, we demonstrate that the dramatic side-chain

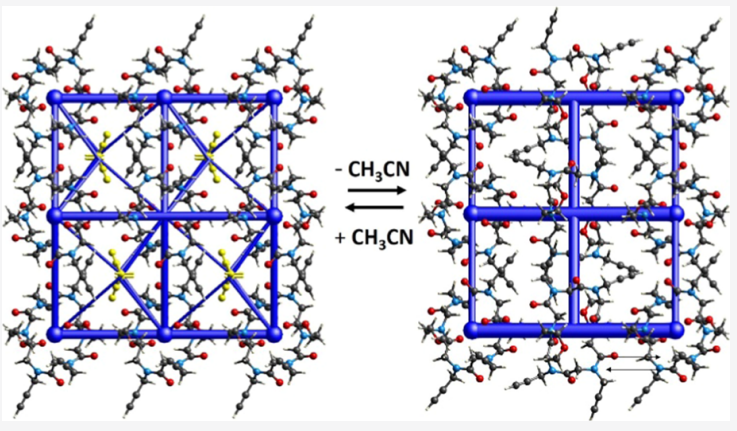
movement is a peculiar feature of the solid-state assembly and is determined by a backbone conformational change that leads to stabilizing $\mathrm{CH}$. O OC backbone-to-backbone interactions tightening the framework upon acetonitrile release. Weak interactions as $\mathrm{CH} \cdots \mathrm{OC}$ and $\mathrm{CH}-\pi$ bonds with the guest molecules are able to reverse the transformation, providing the energy contribution to unzip the framework. We believe that the underlined mechanism could be used as a model system to understand how external stimuli (as temperature, humidity, or volatile compounds) could determine conformational changes in the solid state.

\section{INTRODUCTION}

The dynamic behavior of the biomolecules enables efficient guest recognition and specific substrate conversion in biological processes. The aim of inexhaustible research activity in the field of molecular nanotechnology is the design and synthesis of artificial systems able to combine the recognition abilities of proteins with thermochemical stability. ${ }^{1-3}$

As peptidomimetic compounds, $\mathrm{N}$-substituted polyglycines (or peptoids, see Figure 1 ) $^{4}$ feature useful biological activities

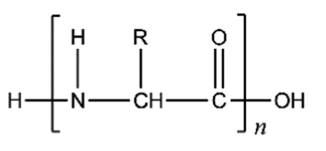

Peptide

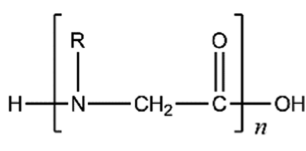

Peptoid
Figure 1. Peptide vs peptoid.

and interesting chemical properties both in solution and in the solid state. ${ }^{5}$ They may represent new motifs on which to base artificial ionophoric antibiotics: ${ }^{6}$ the biological assays indicated in some cases antifungal activity and no toxicity toward red blood cells. ${ }^{7}$ Their ion transport abilities in artificial liposomes have often been related to promising cytotoxic activity on human cancer cell lines. ${ }^{8,9}$ They were used as scaffolds for hybrid glycopeptoid systems, with outstanding multivalent effects in $\alpha$ mannosidase inhibition. ${ }^{10}$ They were also tested as phasetransfer catalysts with performances comparable to crown ethers. ${ }^{11}$ Recently, the discovery of conformational isomerism in cyclic peptoids suggests the application of peptoids in asymmetric synthesis and chiral recognition. ${ }^{12,13}$

Different from with peptides, in peptoids, the side chains are attached to the nitrogen atoms of the oligoamide backbone (Figure 1). ${ }^{14,15}$ Thus, $\mathrm{CH}_{2} \cdots$ OC hydrogen bonds take the place of ordinary $\mathrm{NH}$... OC bonds in peptides. ${ }^{16,17}$

Recently, our group evidenced how environmental changes (temperature, humidity, gas pressure, etc.) may trigger the dynamic behavior of cyclic peptoids in the solid state. ${ }^{18} \mathrm{We}$ established the solvatomorphic behavior of compound $\mathbf{1}$, a cyclic hexapeptoid decorated with four propargyl and two methoxyethyl side chains (Figure 2), which led to the discovery of two

Received: September 10, 2020

Revised: January 5, 2021

Published: January 20, 2021 


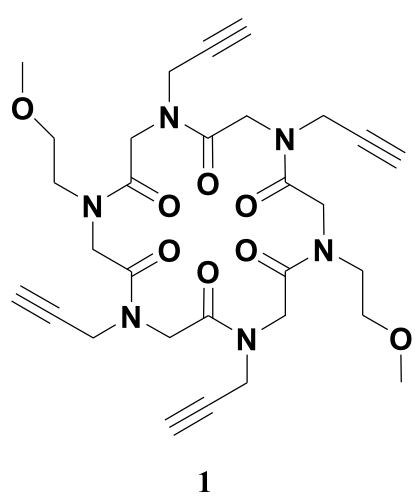

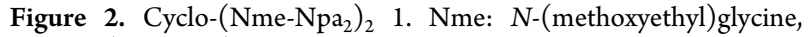
Npa: $N$-(propargyl)glycine.

pure crystalline forms and four solvates. ${ }^{18,19}$ Interestingly, the methanol solvate and the hydrate form result in a stable porous molecular framework, which adsorbs gases as propyne or carbon dioxide but not methane. ${ }^{20}$

Moreover, upon heating, the crystals of the acetonitrile solvate form 1A (Figure 3), release acetonitrile molecules, and undergo

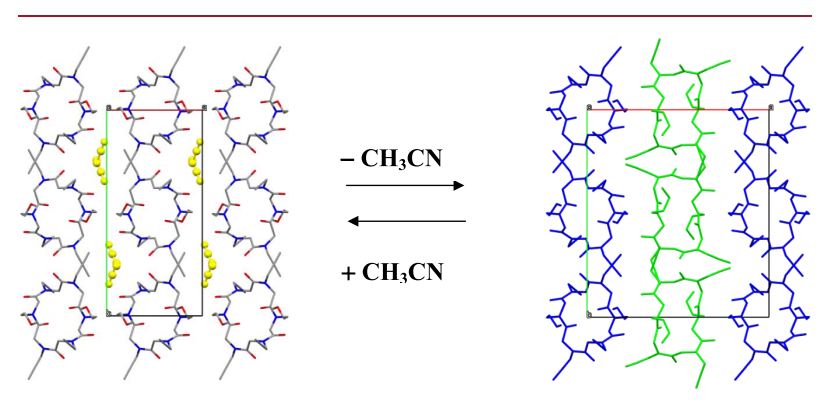

$\mathbf{1 A}$

$1 \mathrm{~B}$

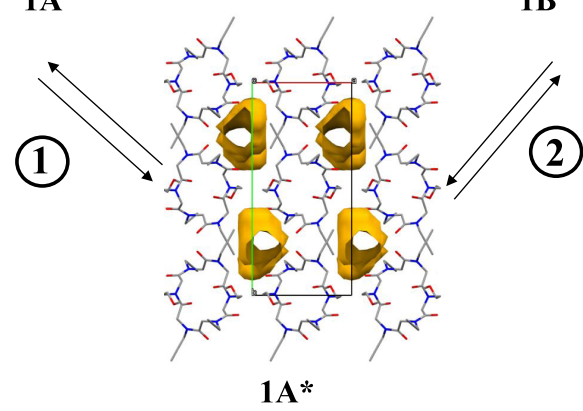

Figure 3. Reversible SCSC transformation from acetonitrile solvate form $1 \mathrm{~A}$ to desolvated form $\mathbf{1 B}$. The process may be divided into two stages, which involve the virtually empty form $1 \mathrm{~A}^{*}$ (which does not correspond to a real intermediate). The crystal packing of $1 \mathrm{~A}, \mathbf{1 B}$, and $1 \mathbf{A}^{*}$ is shown. In $\mathbf{1 A}$, the acetonitrile guest molecule is highlighted in yellow; in 1B, type I molecules are depicted in blue and type II molecules in green; and in $\mathbf{1} \mathbf{A}^{*}$, void channels are represented in yellow. Color types: $\mathrm{C}$, gray; $\mathrm{N}$, blue; and $\mathrm{O}$, red. Hydrogen atoms have been omitted for clarity.

a reversible single crystal-to-single crystal (SCSC) transformation into crystal form 1B (Figure 3) with a remarkable conformational change of the macrocycle: two propargyl side chains move by $113^{\circ}$ to form an unprecedented "CH- $\pi$ zipper". Then, upon acetonitrile adsorption, the " $\mathrm{CH}-\pi$ zipper" opens up and the crystal form $\mathbf{1 B}$ transforms back to $\mathbf{1 A}$. $^{18}$
Here, we report the results of conformational and lattice energy studies of the acetonitrile solvate and desolvated crystal forms $\mathbf{1 A}$ and $\mathbf{1 B}$, with the aim to investigate the energetic landscape beyond the peculiar dynamic behavior of $\mathbf{1}$.

Hirshfeld surfaces and energy framework analysis allowed us to analyze and visualize the contributions of intermolecular interactions, as weak $\mathrm{CH} \cdots \mathrm{OC}$ hydrogen bonds and $\mathrm{CH}-\pi$ interactions, toward the crystal packing in $\mathbf{1 A}$ and $\mathbf{1 B}$.

Periodic quantum chemical calculations, based on $\mathrm{HF}-3 \mathrm{c}$ Hamiltonian, offered the possibility to further probe the structure-energy relationship in the reversible SCSC transformation from $\mathbf{1 A}$ to $\mathbf{1 B}$.

\section{MATERIALS AND METHODS}

For all calculations, the lengths of $\mathrm{X}-\mathrm{H}$ bonds were normalized using the standard $\mathrm{X}-\mathrm{H}$ distances $(\mathrm{X}=\mathrm{C}, \mathrm{O}, \mathrm{N}) .^{21}$ Thus, the reported $\mathrm{X}-\mathrm{H}$ distances and $\mathrm{X} \cdots \mathrm{H}$ contacts refer to the recalculated structures and are not equal to those calculated from the original cif files.

Gas-Phase Energy Optimization. Gas-phase energy optimization for the cyclopeptoid molecule in $\mathbf{1 A}$ and $\mathbf{1 B}$ were performed with Gaussian $09,^{22}$ using a polarized valence triple-zeta basis set (cc-pVTZ) and B97-D3 method, a Grimme's modified density functional, ${ }^{23}$ which includes the D3 empirical dispersion correction. ${ }^{24}$

Least-squares overlay of pairs of structures was performed using Mercury, which also provides root-mean-square deviation (RMSD) values. $^{25}$

Hirshfeld Surface and Energy Framework Analysis. Hirshfeld surface analysis ${ }^{26-29}$ was performed with CrystalExplorer 17.5. . $^{30}$ Intermolecular interactions were calculated with the B3LYP level of theory using the 6-31G(d,p) basis set for all atoms and include electrostatic, polarization, dispersion, and exchange-repulsion terms, as reported by Turner et al. ${ }^{31}$

To provide a graphical representation of the intermolecular interaction energies, CrystalExplorer was used to represent the energy frameworks. ${ }^{32}$

Lattice Energy Calculations. Lattice energy calculations were performed using the CLP-Pixel package with a Pixel condensation level of $4 .^{33-35}$ The total lattice energy is partitioned into its Coulombic, polarization, dispersion, and repulsion contributions. In CLP-Pixel, the Coulombic terms are handled by Coulomb's law and calculated by a numerical integral equivalent to the standard analytical form; the polarization terms are calculated in the linear dipole approximation, with the incoming electric field acting on local polarizabilities and generating a dipole with its associated dipole separation energy; dispersion terms are simulated in London's inverse sixth-power approximation, involving ionization potentials and polarizabilities; repulsion is presented as a modulated function of wave function overlap.

Periodic HF-3c Calculations. The energy values of $1 \mathrm{~A}, 1 \mathrm{~A}^{*}$, and 1B were calculated using the developer version of the software Crystal14. ${ }^{36,37}$ All of the calculations were performed using the low-cost empirical corrected HF-3c method; ${ }^{38}$ in the HF-3c- $\left(0.27 \mathrm{~s}_{8}\right)$ scaled version, refined by some of us to compute fast and accurate molecular crystals properties. ${ }^{39}$ Using this methodology, we run the HartreeFock calculations with the minimal quality basis set called MINIX $^{40}$ and three semiempirical corrections to the HF energy: (i) the inclusion of long-range London dispersion interactions, (ii) the basis set superposition error (BSSE), and (iii) short-range basis set incompleteness (SRB).

Full optimization of the crystal structures, including the unit cell parameters, was performed at $\Gamma$ point using the analytical gradient method by upgrading the Hessian with the Broyden-FletcherGoldfarb-Shanno (BFGS) algorithm. ${ }^{41-43}$ Crystal14 default tolerances were applied: $10^{-7} \mathrm{Ha}$ for the energy convergence during the geometry optimization; $10^{-6} \mathrm{Ha}$ as truncation criteria for bioeletronic integrals of the Coulomb series and $10^{-14} \mathrm{Ha}$ as that of the exchange series. Choosing to run the calculations using just $1 \mathrm{k}$ point (shrinking factor 1) was justified after comparing calculations with 10 and $30 \mathrm{k}$ 
points, without finding significant differences, in spite of much less costly calculations.

\section{RESULTS AND DISCUSSION}

Molecular Structures: Comparison between $1 \mathrm{~A}$ and 1B. Both X-ray molecular structures of 1 in crystal forms $1 \mathrm{~A}$ and 1B show a crystallographic inversion center and exhibit a cctcct (c $=$ cis; $t=$ trans) sequence of distorted amide bonds (Table S1 in the Supporting Information). ${ }^{18}$

In crystal form 1A, two methoxyethyl and two propargyl side chains point vertically up and down with respect to the macrocycle plane, while the two remaining propargyl side chains extend horizontally in the equatorial plane. In crystal form 1B, there are two crystallographically independent cyclopeptoid molecules, named type I and type II molecules (in blue and green, respectively, in Figure 3). Type I molecules (blue) show only slight differences with respect to form 1A. Type II molecules (green) feature vertical methoxyethyl side chains, while all propargyl side chains extend horizontally in the equatorial plane.

Thus, cis propargyl $\chi_{1}$ torsion angle changes from 118.1(2) to $-129.4(2)^{\circ}$ during the transformation from crystal form 1 A to $\mathbf{1 B}$ and vice versa (Table S1 and Figure S1 in the Supporting Information). ${ }^{18}$

Besides the remarkable change of orientation of two propargyl side chains, also a backbone conformational change occurs. Type II molecules (green in Figure 3) have a more extended rectangular shape with respect to type I molecules (blue in Figure 3), as is evident considering the distance between and

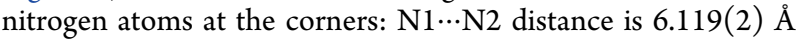
for type I molecules and increases to 6.960(2) $\AA$ for type II molecules.

Indeed, the backbone conformation in type II molecules adapts to the ideal type I $\beta$-turn structure of polypeptides. ${ }^{18,44}$

We would like to point out that the shape difference between type I and II molecules may be related to the presence of shorter

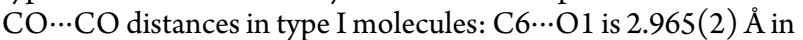

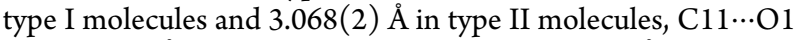
is $3.169(2) \AA$ in type I molecules and $3.615(2) \AA$ in type II molecules, and $\mathrm{C} 11 \cdots \mathrm{O} 2$ is $3.260 \AA$ in type I molecules and $3.480 \AA$ in type II molecules (Figure 4 and Table S2 in the Supporting Information).

CO $\cdots \mathrm{CO}$ distances shorter than $3.2 \AA$ (i.e., the sum of van der Waals radii) may be attributed to $\mathrm{n} \rightarrow \pi^{*}$ interactions. ${ }^{45}$ The importance of such interactions in peptides, proteins, polymer like poly(lactic acid) (PLA), and linear peptoids have been recently pointed out. ${ }^{45-47}$

Gas-Phase Energy Optimization. To estimate the energy differences of the macrocycle conformations in $1 \mathrm{~A}$ and $1 \mathrm{~B}$, a gasphase optimization was performed with Gaussian $09 .^{22}$

The optimized gas-phase molecular structures of $\mathbf{1 A}$ and type I molecules in form $\mathbf{1 B}$ have equivalent energy and differ from the X-ray molecular structures by RMSDs of 0.4507 and 0.4271 $\AA$, respectively (Figure S2a,b in the Supporting Information and Figure 5a).

The optimized gas-phase molecular structure of type II molecules in form $\mathbf{1 B}$ is less energetically favored by $21.55 \mathrm{~kJ} /$ mol with respect to type I molecules. Interestingly, it differs from the X-ray molecular structure by a RMSD of $0.7525 \AA$. In detail, the orientation of the moving cis propargyl side chains is completely different, being vertical and not anymore horizontal with respect to the macrocycle plane (Figure S2c,d in the Supporting Information and Figure $5 b$ ). This suggests that the

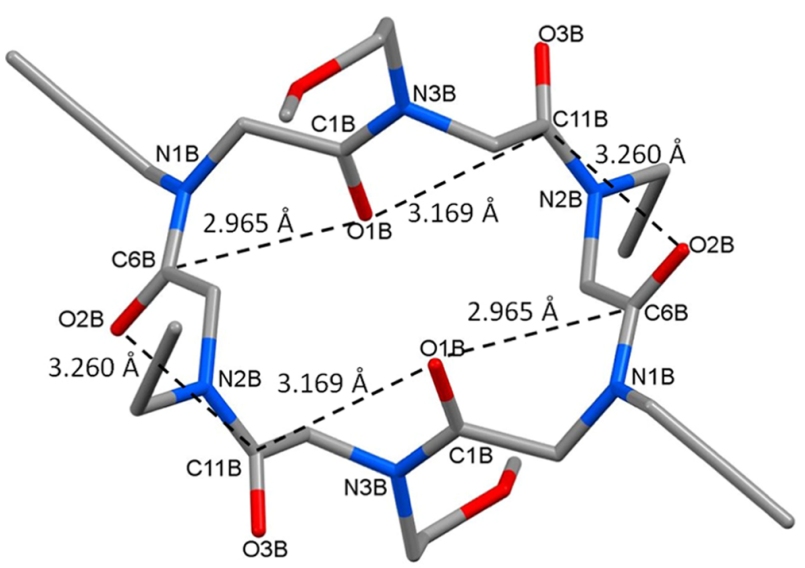

(a)

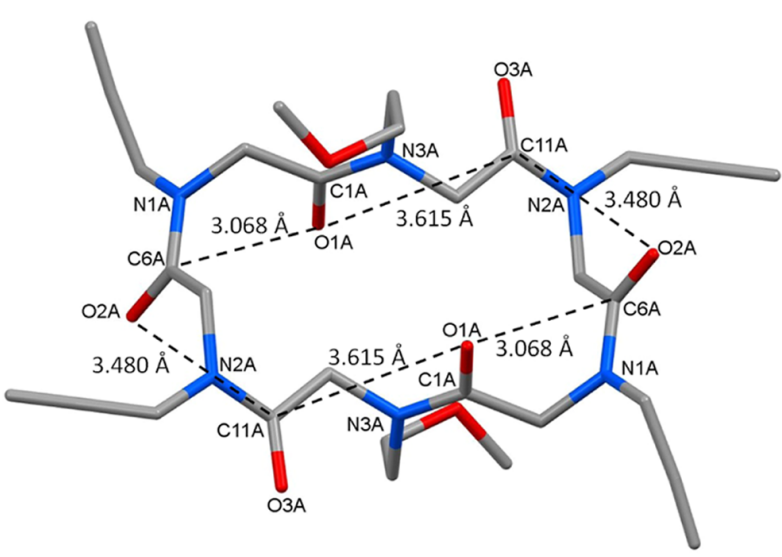

(b)

Figure 4. Shortest $\mathrm{CO} \cdots \mathrm{CO}$ distances in (a) type I and (b) type II molecules in crystal form 1B. Hydrogen atoms have been omitted for clarity.

side-chain movement is a peculiar feature of the solid-state assembly and is determined by the possibility for the propargyl groups to form a mutual $\mathrm{CH}-\pi$ zipper in the solid state.

X-ray Crystal Structures, Hirshfeld Surface Analysis, and Lattice Energy Calculations. Hirshfeld surface analysis and energy calculations allowed us to detect quantitatively the main structural features of the crystal packing in crystal forms $\mathbf{1 A}$ and 1B. In Tables 1 and 2, the intermolecular distances $(\AA)$, angles $\left({ }^{\circ}\right)$, and interaction energies $(\mathrm{kJ} / \mathrm{mol})$ in the host framework of crystal forms $\mathbf{1 A}$ and $\mathbf{1 B}$, respectively, as calculated using PIXEL ${ }^{33-35}$ and CrystalExplorer, are reported. ${ }^{30}$ The Hirshfeld surface analysis highlights the short contacts between the cyclic peptoid molecules: red zones correspond to the shortest intermolecular distances. As for proteins, molecular interactions in peptoid crystals may be classified as backbone-to backbone interactions, backbone-to-side chain interactions, and side chain-to-side chain interactions.

Intermolecular Interactions in Crystal Form 1A. The main motif in crystal form 1A is the columnar arrangement of macrocycles (Motif 1; Figure 6 and Table 1) by means of backbone-to-side chain $\mathrm{CH}$... OC interactions between the 


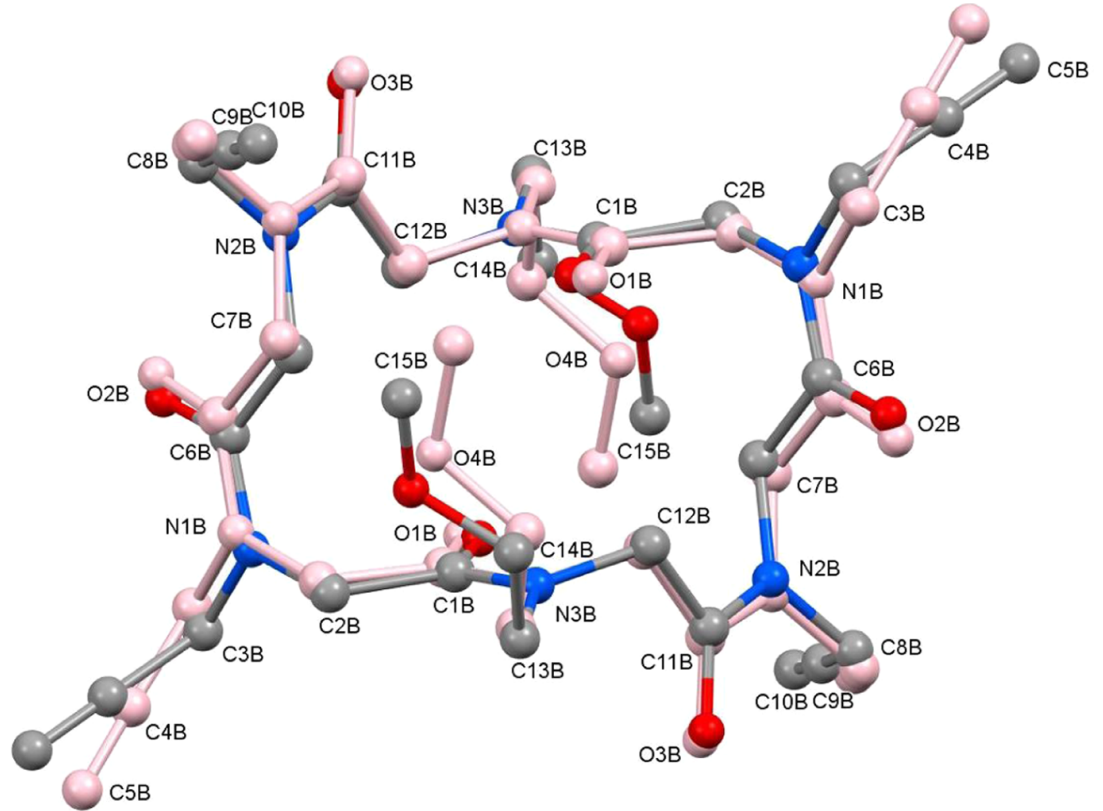

(a)

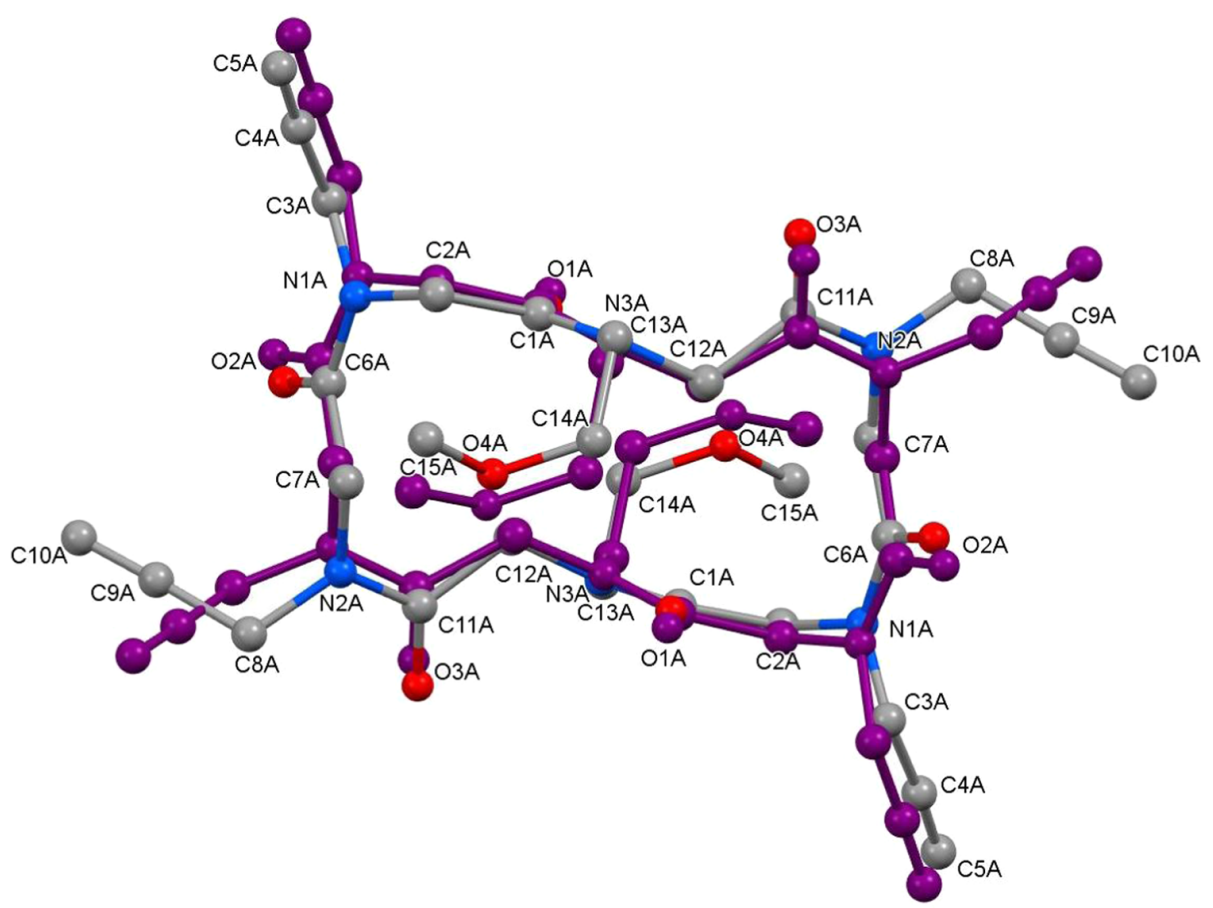

(b)

Figure 5. Structural overlays of (a) type I molecules in 1B before and after the optimization (light pink), RMSD $0.427 \AA$, and (b) type II molecules in $1 \mathrm{~B}$ before and after the optimization (purple), RMSD $0.760 \AA$. Element colors are used for X-ray molecular structures: C, gray; N, blue; and O, red. Hydrogen atoms have been omitted for clarity.

vertical cis propargyl side chain and the carbonyl oxygen atom of

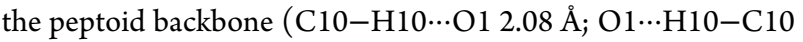
$\left.161.6^{\circ}\right)$. In this way, the cyclopeptoid molecules stack on top of each other to form columns that develop along the shortest $c$-axis through vertical propargyl side chains, which act as pillars.

Moreover, cyclic peptoids interact along the a-axis through backbone-to-side chain $\mathrm{CH}$... OC interactions between the carbonyl oxygen atoms and the methylene hydrogen atom of

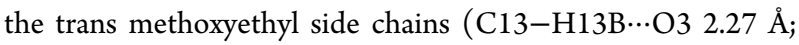
O3 $\cdots \mathrm{H} 13 \mathrm{~B}-\mathrm{C} 13$ 141.2 ${ }^{\circ}$; Motif 2; Figure 6 and Table 1).

Further, in the last motif (Motif 3; Figure 6 and Table 1), the macrocycles interact in the $b c$-plane by means of backbone-toside chain interactions and side chain-to-side chain $\mathrm{CH} \cdots \mathrm{OC}$ 
Table 1. List of Intermolecular Distances $(\AA)$, Angles $\left({ }^{\circ}\right)$, and Interaction Energies $(\mathrm{kJ} / \mathrm{mol})$ in Crystal Form $1 \mathrm{~A}^{a, b}$

\begin{tabular}{|c|c|c|c|c|c|c|c|c|c|c|}
\hline motif & $\mathrm{D}-\mathrm{H} \cdots \mathrm{A}$ & $\begin{array}{c}\mathrm{H} \cdots \mathrm{A} \\
(\AA)\end{array}$ & $\begin{array}{c}\mathrm{D}-\mathrm{H} \cdots \mathrm{A} \\
(\mathrm{deg})\end{array}$ & symm. op. & $\begin{array}{c}\text { centroid distance } \\
(\AA)\end{array}$ & $E_{\text {Coul }}$ & $E_{\mathrm{Pol}}$ & $E_{\text {Disp }}$ & $E_{\text {Rep }}$ & $E_{\mathrm{Tot}}$ \\
\hline \multirow[t]{2}{*}{1} & $\mathrm{C} 10-\mathrm{H} 10 \cdots \mathrm{O} 1$ & 2.08 & 161.6 & $x, y,-1+z$ & 8.500 & -78.0 & -30.5 & -96.5 & 111.6 & -93.6 \\
\hline & $\mathrm{C} 14-\mathrm{H} 14 \mathrm{~B} \cdots \mathrm{C} 10 \equiv$ & 2.71 & 120.2 & $x, y, 1+z$ & & -70.3 & -17.3 & -98.2 & 116.6 & -100.5 \\
\hline \multirow[t]{2}{*}{2} & $\mathrm{C} 13-\mathrm{H} 13 \mathrm{~B} \cdots \mathrm{O} 3$ & 2.27 & 141.2 & $-1+x, y, z$ & 9.773 & -30.4 & -15.5 & -35.9 & 40.8 & -41.0 \\
\hline & & & & $1+x, y, z$ & & -27.6 & -13.9 & -39.1 & 39.9 & -49.0 \\
\hline \multirow[t]{5}{*}{3} & $\mathrm{C} 8-\mathrm{H} 8 \mathrm{~A} \cdots \mathrm{O} 2$ & 2.33 & 138.4 & $1-x,-1 / 2+y, 1 / 2-z$ & 11.309 & -23.1 & -9.1 & -35.4 & 32.7 & -35.0 \\
\hline & $\mathrm{C} 5-\mathrm{H} 5 \cdots \mathrm{O} 4$ & 2.38 & 129.7 & $1-x, 1 / 2+y, 1 / 2-z$ & & & & & & \\
\hline & & & & & & -21.4 & -5.5 & -39.4 & 34.1 & -40.0 \\
\hline & & & & $1-x,-1 / 2+y, 3 / 2-z$ & & & & & & \\
\hline & & & & $1-x, 1 / 2+y, 3 / 2-z$ & & & & & & \\
\hline \multirow[t]{2}{*}{$4-s$} & $\mathrm{C} 13-\mathrm{H} 13 \mathrm{~A} \cdots \mathrm{N} 4$ & 2.64 & 124.3 & $x, y, z$ & 6.626 & -13.1 & -4.8 & -11.7 & 11.5 & -18.1 \\
\hline & & & & & & -12.4 & -4.7 & -12.2 & 11.9 & -19.9 \\
\hline \multirow[t]{2}{*}{$5-s$} & $\mathrm{C} 17-\mathrm{H} 17 \mathrm{C} \cdots \mathrm{O} 3$ & 2.36 & 141.8 & $1+x, y, z$ & 7.559 & -10.2 & -3.7 & -10.9 & 8.9 & -15.8 \\
\hline & $\mathrm{C} 17-\mathrm{H} 17 \mathrm{~B} \cdots \mathrm{O} 2$ & 2.60 & 150.2 & & & -10.4 & -3.4 & -12.1 & 10.4 & -17.6 \\
\hline
\end{tabular}

${ }^{a}$ Energy values calculated by PIXEL are displayed in plain text and those calculated by CrystalExplorer are in bold face. ${ }^{b}$ Interactions between host framework and acetonitrile guest molecules are indicated with an "s".

Table 2. List of Intermolecular Distances $(\AA)$, Angles $\left({ }^{\circ}\right)$, and Interaction Energies $(\mathrm{kJ} / \mathrm{mol})$ in Crystal Form $1 \mathrm{~B}^{a}$

\begin{tabular}{|c|c|c|c|c|c|c|c|c|c|c|}
\hline motif & $\mathrm{D}-\mathrm{H} \cdots \mathrm{A}$ & $\mathrm{H} \cdots \mathrm{A}(\AA)$ & $\mathrm{D}-\mathrm{H} \cdots \mathrm{A}\left({ }^{\circ}\right)$ & symm. op. & $\begin{array}{c}\text { centroid distance } \\
(\AA)\end{array}$ & $E_{\text {Coul }}$ & $E_{\mathrm{Pol}}$ & $E_{\text {Disp }}$ & $E_{\text {Rep }}$ & $E_{\mathrm{Tot}}$ \\
\hline \multirow[t]{2}{*}{$1 \mathrm{I}-\mathrm{I}$} & $\mathrm{C} 10 \mathrm{~B}-\mathrm{H} 10 \mathrm{~B} \cdots \mathrm{O} 1 \mathrm{~B}$ & 2.03 & 167.5 & $x, y,-1+z$ & 8.472 & -78.9 & -31.6 & -94.7 & 112.1 & -93.1 \\
\hline & & & & $x, y, 1+z$ & & -71.4 & -18.6 & -97.6 & 116.7 & -102.1 \\
\hline \multirow[t]{4}{*}{$2 \mathrm{I}-\mathrm{I}$} & $\mathrm{C} 8 \mathrm{~B}-\mathrm{H} 8 \mathrm{D} \cdots \mathrm{O} 2 \mathrm{~B}$ & 2.24 & 138.5 & $-x, 1 / 2+y, 1 / 2-z$ & 11.015 & -20.9 & -8.5 & -35.7 & 33.9 & -31.2 \\
\hline & $\mathrm{C} 5 \mathrm{~B}-\mathrm{H} 5 \mathrm{~B} \cdots \mathrm{O} 4 \mathrm{~B}$ & 2.56 & 112.9 & $-x,-1 / 2+y, 1 / 2-z$ & & -19.1 & -5.4 & -40.6 & 34.8 & -38.0 \\
\hline & & & & $-x,-1 / 2+y, 3 / 2-z$ & & & & & & \\
\hline & & & & $-x, 1 / 2+y, 3 / 2-z$ & & & & & & \\
\hline \multirow[t]{5}{*}{$3 \mathrm{II}-\mathrm{II}$} & $\mathrm{C} 7 \mathrm{~A}-\mathrm{H} 7 \mathrm{~B} \cdots \mathrm{O} 2 \mathrm{~A}$ & 2.13 & 169.9 & $1-x,-1 / 2+y, 1 / 2-z$ & 11.015 & -32.9 & -15.4 & -53.7 & 49.8 & -52.2 \\
\hline & & & & $1-x,-1 / 2+y, 3 / 2-z$ & & & & & & \\
\hline & C10A-H10A $\cdots \mathrm{O} 4 \mathrm{~A}$ & 2.24 & 126.7 & & & -30.1 & -10.5 & -59.1 & 51.1 & -59.6 \\
\hline & $\mathrm{C} 8 \mathrm{~A}-\mathrm{H} 8 \mathrm{~B} \cdots \mathrm{C} 9 \mathrm{~A} \equiv$ & $2.71,2.78$ & $163.9,141.1$ & $1-x, 1 / 2+y, 1 / 2-z$ & & & & & & \\
\hline & C10A & & & $1-x, 1 / 2+y, 3 / 2-z$ & & & & & & \\
\hline \multirow[t]{2}{*}{$4 \mathrm{II}-\mathrm{II}$} & C15A-H15A $\cdots$ O1A & 2.47 & 171.4 & $x, y,-1+z$ & 8.472 & -31.7 & -9.8 & -47.9 & 38.8 & -50.7 \\
\hline & & & & $x, y, 1+z$ & & -28.6 & -5.8 & -51.3 & 36.9 & -56.5 \\
\hline \multirow[t]{6}{*}{$5 \mathrm{I}-\mathrm{II}$} & $\mathrm{C} 2 \mathrm{~A}-\mathrm{H} 2 \mathrm{~B} \cdots \mathrm{O} 3 \mathrm{~B}$ & 2.16 & 151.1 & $x, y, z$ & 8.944 & -56.9 & -21.2 & -61.1 & 69.2 & -70.0 \\
\hline & $\mathrm{C} 2 \mathrm{~B}-\mathrm{H} 2 \mathrm{D} \cdots \mathrm{O} 3 \mathrm{~A}$ & 2.23 & 154.6 & $1+x, y, z$ & & -54.3 & -15.3 & -66.1 & 72.9 & -81.2 \\
\hline & $\mathrm{C} 13 \mathrm{~A}-\mathrm{H} 13 \mathrm{~B} \cdots \mathrm{O} 3 \mathrm{~B}$ & 2.50 & 137.1 & $-1+x, y, z$ & & & & & & \\
\hline & $\mathrm{C} 13 \mathrm{~B}-\mathrm{H} 13 \mathrm{D} \cdots \mathrm{O} 3 \mathrm{~A}$ & 2.54 & 135.8 & & & & & & & \\
\hline & $\mathrm{C} 13 \mathrm{~B}-\mathrm{H} 13 \mathrm{D} \cdots \mathrm{C} 1 \mathrm{~A}$ & 2.72 & 144.5 & & & & & & & \\
\hline & $\mathrm{C} 8 \mathrm{~A}-\mathrm{H} 8 \mathrm{~A} \cdots \mathrm{C} 5 \mathrm{~B} \equiv$ & 2.73 & 130.8 & & & & & & & \\
\hline
\end{tabular}

${ }^{a}$ Energy values calculated by PIXEL are displayed in plain text and those calculated by CrystalExplorer are in bold face.

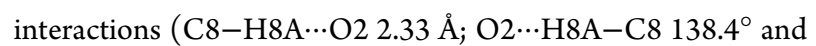

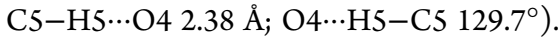

Regarding the acetonitrile guest molecules, they occupy the voids between the macrocycle columns, forming channels parallel to the $c$-axis. Acetonitrile molecules are weakly bound to the host framework (Motif 4-s and Motif 5-s; Figure 6 and Table 1): the main interactions involve the acetonitrile methyl hydrogen atoms and backbone oxygen atoms $(\mathrm{C} 17-\mathrm{H} 17 \mathrm{C} \cdots \mathrm{O} 3$ $2.36 \AA$ A $\mathrm{O} 3 \cdots \mathrm{H} 17 \mathrm{C}-\mathrm{C} 17 \quad 141.8^{\circ} ; \mathrm{C} 17-\mathrm{H} 17 \mathrm{~B} \cdots \mathrm{O} 22.60 \AA$ $\left.\mathrm{O} 3 \cdots \mathrm{H} 17 \mathrm{C}-\mathrm{C} 17150.2^{\circ}\right)$ and the acetonitrile nitrogen atom and the methylene hydrogen atom of the trans methoxyethyl

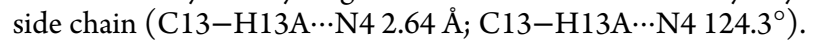
Moreover, acetonitrile molecules are mutually linked by means of the $\mathrm{CH}-\pi$ interactions (C16 $\cdots$ H17A $2.72 \AA$; N $4 \cdots$ H17A 2.75 Å; $\left.\mathrm{C} 16 \cdots \mathrm{H} 17 \mathrm{~A}-\mathrm{C} 17150.5^{\circ}\right)$.

Intermolecular Interactions in Crystal Form 1B. In crystal form 1B, there are two crystallographically independent molecules (type I and type II molecules) in the asymmetric unit and therefore two Hirshfeld surfaces are considered.
Intermolecular interactions may be divided into type I-type I, type II-type II, and type I-type II interactions.

The solid-state assembly of type I molecules is very similar to that observed in crystal form 1A: the Hirshfeld surface shows the same red zones, corresponding to strong columnar interactions via $\mathrm{CO} \cdots \mathrm{HC}$ hydrogen bonds. In Motif $1 \mathrm{I}-\mathrm{I}$ (Figure 7 and Table 2), the main interactions are represented by backbone-toside chains $\mathrm{CO} \cdots \mathrm{HC}$ interactions, involving the backbone carbonyl atom and the vertical propargyl side chains (C10B-

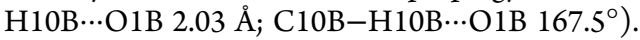

Motif 2 I-I is analogous to Motif 3 in crystal form 1A and characterized by the arrangement of the cyclic peptoids in the $b c$ plane through $\mathrm{CH} \cdots \mathrm{OC}$ interactions between the vertical propargyl side chains and the carbonyl oxygen atoms (C8B$\mathrm{H} 8 \mathrm{D} \cdots \mathrm{O} 2 \mathrm{~B} 2.24 \AA \AA$; O2B $\cdots \mathrm{H} 8 \mathrm{D}-\mathrm{C} 8 \mathrm{~B} 138.5^{\circ}$ ).

Notably, the columnar arrangement of type II molecules (Motif 4 II-II; Table 2 and Figure 7) is not the main interaction for type II molecules but is almost energetically equivalent to the Motif 3 II-II (Table 2 and Figure 7). This corresponds to the 

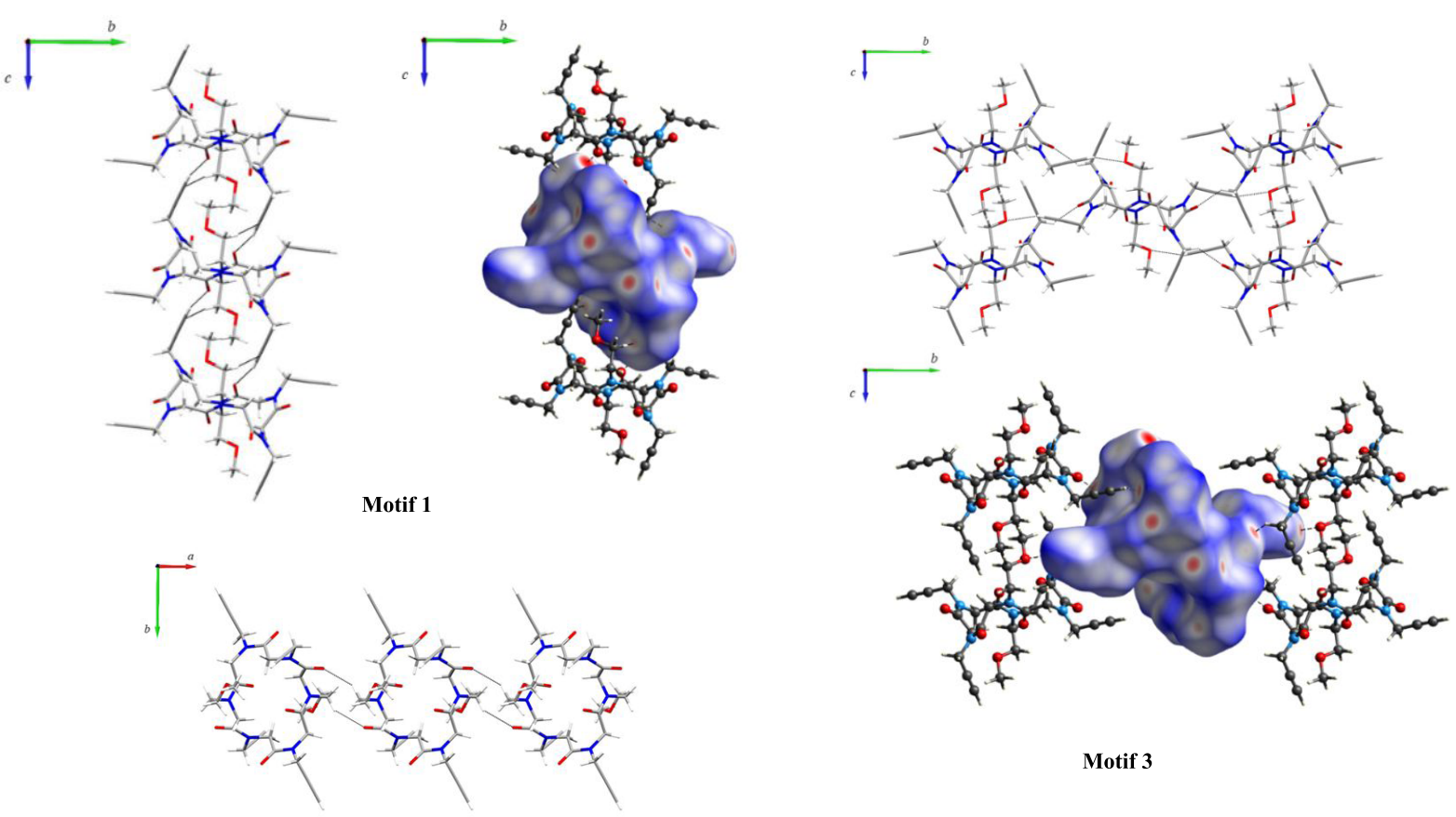

Motif 3
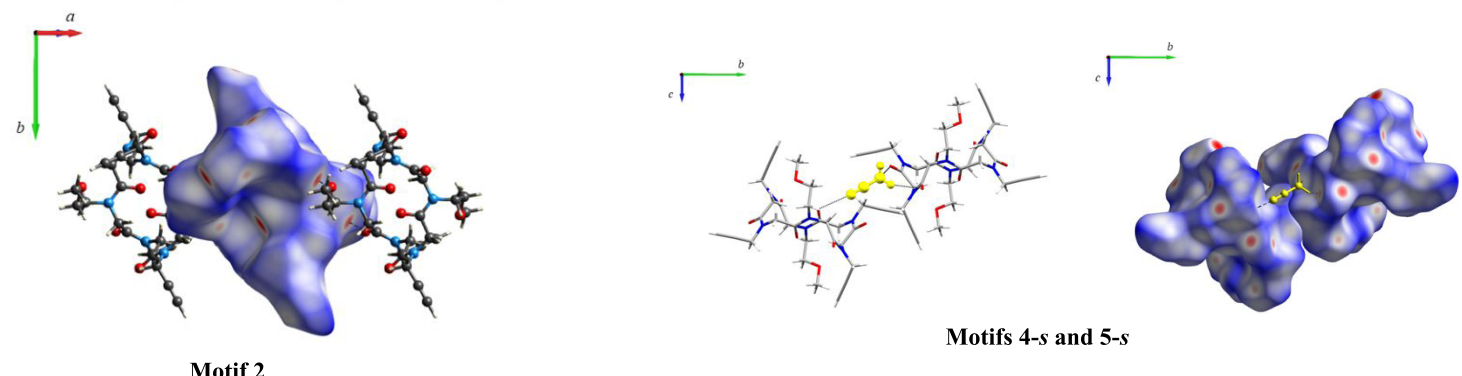

Figure 6. Motifs and Hirshfeld surfaces mapped with $d_{\text {norm }}$ for 1A.

layered arrangement of peptoid type II molecules (in the $b c$ plane) through backbone-to-backbone $\mathrm{CH}$... OC interactions and side-chain $\mathrm{CH}-\pi$ interactions (Motif $3 \mathrm{II}-\mathrm{II}$ in Figure 7). In detail, backbone-to-backbone $\mathrm{CH} \cdots \mathrm{OC}$ interactions (C7A-

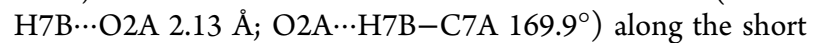
side of the macrocycle were recently identified as a recurring assembly mode for cyclic hexapeptoids. ${ }^{48}$ Moreover, this assembly mode allows the formation of a $\mathrm{CH}-\pi$ zipper (C8A-

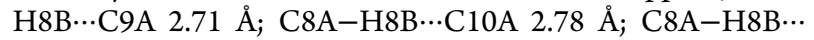
C9A $163.9^{\circ}$; $\mathrm{C} 8 \mathrm{~A}-\mathrm{H} 8 \mathrm{~B} \cdots \mathrm{C} 10 \mathrm{~A} 141.1^{\circ}$ ) by mutual $\mathrm{CH}-\pi$ interactions between the horizontal propargyl side chains of adjacent columns. These are exactly the propargyl side chains that rotate by $113^{\circ}$ during the SCSC transformation!

Regarding the columnar arrangement of type II molecules (Motif 4 II-II; Table 2 and Figure 7), we would like to point out that different from with type I molecules and crystal form $1 \mathrm{~A}$, the vertical methoxyethyl side chains work as pillars instead of the propargyl side chains, providing $\mathrm{CH} \cdots \mathrm{OC}$ interaction between methyl hydrogen atoms and the backbone oxygen atoms

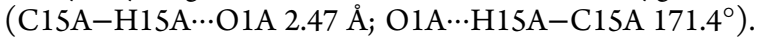

The interaction between type I and type II molecules in crystal form 1B (Motif 5 I-II; Table 2 and Figure 7) occurs along the $a$-axis, thus replacing Motif 2 in crystal form 1A. Sideby-side backbone interactions form a ribbon of alternating type I and type II macrocycles along the $a$-axis: type I backbone methylene hydrogen atoms interact with type II carbonyl oxygen

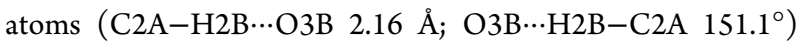
and vice versa $(\mathrm{C} 2 \mathrm{~B}-\mathrm{H} 2 \mathrm{D} \cdots \mathrm{O} 3 \mathrm{~A} 2.23 \AA$; O $3 \mathrm{~A} \cdots \mathrm{H} 2 \mathrm{D}-\mathrm{C} 2 \mathrm{~B}$ $\left.154.6^{\circ}\right)$. Other backbone-to-side chain interactions and side chain-to-side chain interactions (see Motif 5 I-II in Table 2) help to stabilize the assembly.

Energy Framework Analysis. Energy framework analysis helped greatly to visualize the interaction motifs shown in Figures 6 and 7 and listed in Tables 1 and 2, respectively. In Figures $8-10$, the energies between molecular pairs are represented as cylinders joining the centers of mass of the molecules, with the cylinder radius proportional to the magnitude of the interaction energy.

Inspecting Figures $8 \mathrm{a}$ and $9 \mathrm{a}$, it is evident that in crystal form 1A the columnar arrangement of cyclic peptoids along the shortest axis (Motif 1) is the dominant motif compared to Motifs 2 and 3.

In crystal form 1B, type I molecules feature the same columnar arrangement of form $\mathbf{1 A}$ (see Figure $8 \mathrm{~b}$,a, and correspondingly Motif $1 \mathrm{I}-\mathrm{I}$ in $\mathbf{1 B}$ and Motif 1 in $\mathbf{1 A}$ in Tables 2 and 1 , respectively), while type II molecules are characterized by a less efficient columnar arrangement (Motif 4 II-II; Table 2), represented by a smaller cylinder radius in Figure 8c.

Thus, the columnar arrangement is the second most favored assembly for type II molecules, the first being the layered arrangement of type II molecules in the $b c$-plane (Motif 3 II-II; 


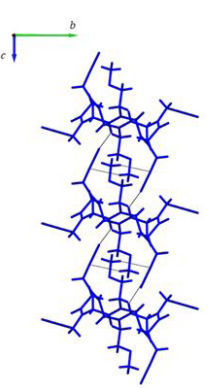

Motif 1 I-I
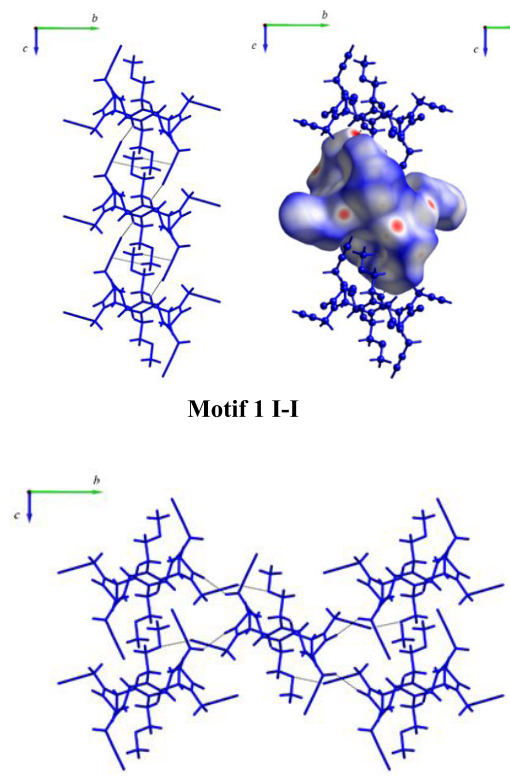

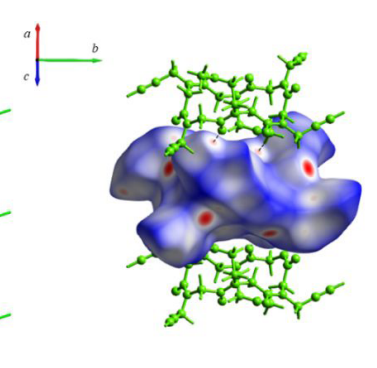

Motif 4 II-II

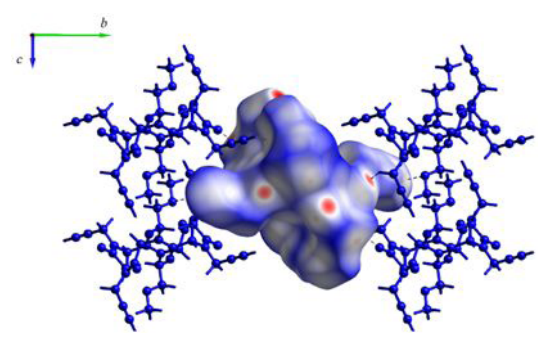

Motif 2 I-I

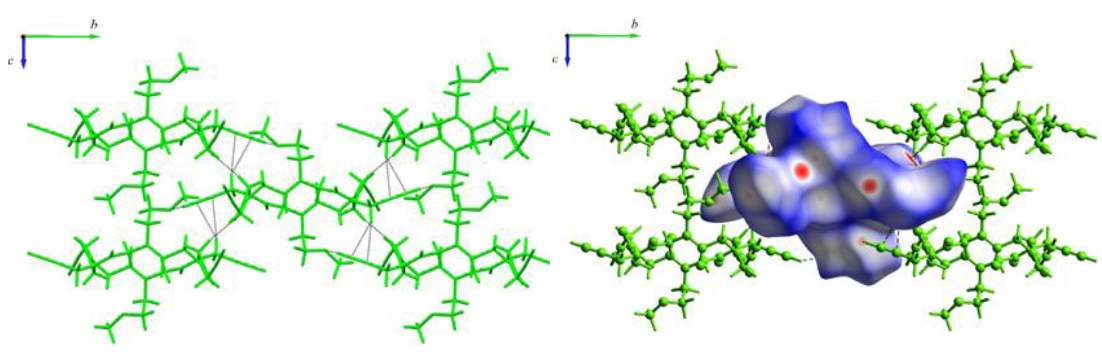

Motif 3 II-II
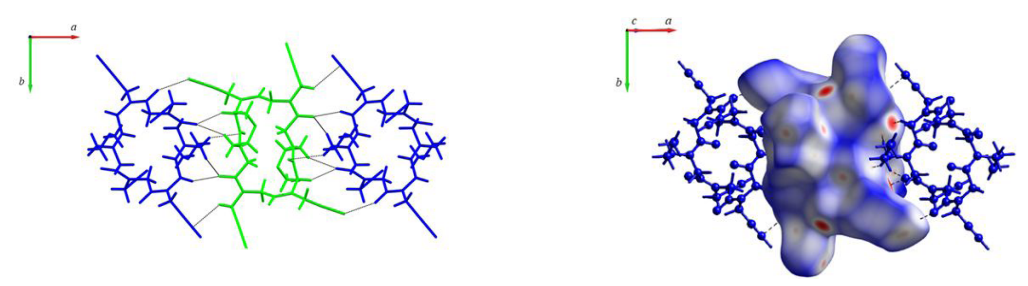

Motif 5 I-II

Figure 7. Motifs and Hirshfeld surfaces mapped with $d_{\text {norm }}$ for 1B. CH- $\pi$ zipper is depicted in MOTIF 3 II-II.

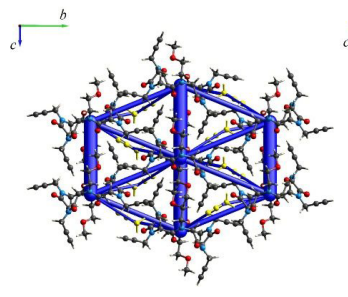

(a) $1 \mathbf{A}$

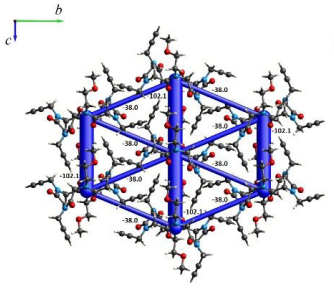

(b) I-I 1B

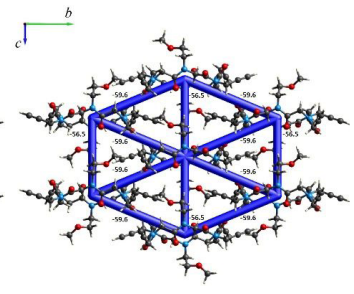

(c) II-II 1B

Figure 8. Energy frameworks as viewed along the $a$-axis in crystal form 1A (acetonitrile molecules are highlighted in yellow) for type I molecules in 1B and type II molecules in 1B. Cylinder radius is scaled to 80; interaction energies with magnitudes smaller than $-10 \mathrm{~kJ} \mathrm{~mol}^{-1}$ have been omitted.

Figure $8 \mathrm{c}$ and Table 2), characterized by the formation of the $\mathrm{CH}-\pi$ zipper.
By inspecting Figure 9, it is evident that interactions between cyclic peptoid molecules along the $a$-axis in 1A (Motif 2; Table 


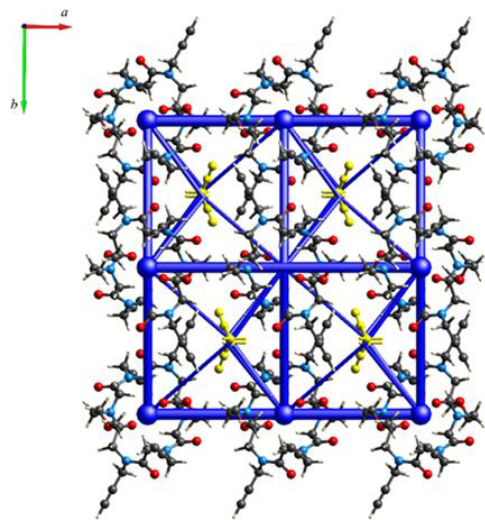

(a) $1 \mathrm{~A}$

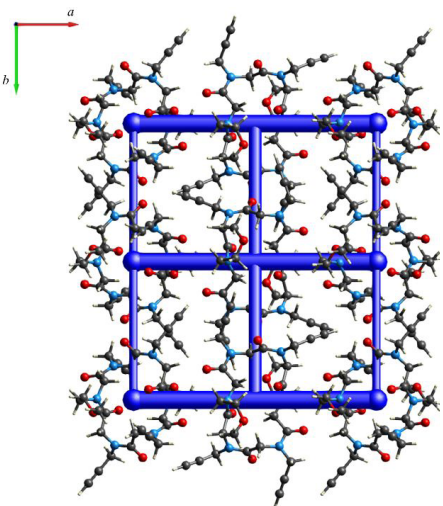

(b) $\mathbf{1 B}$

Figure 9. Energy frameworks for the host framework in $\mathbf{1 A}$ and $\mathbf{1 B}$ as viewed along the $c$-axis. Cylinder radius is set to 80; interaction energies with magnitudes smaller than $-10 \mathrm{~kJ} \mathrm{~mol}^{-1}$ were omitted.

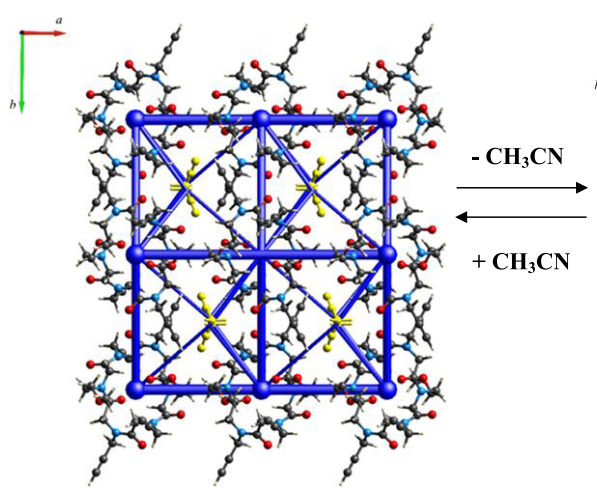

$1 \mathbf{A}$

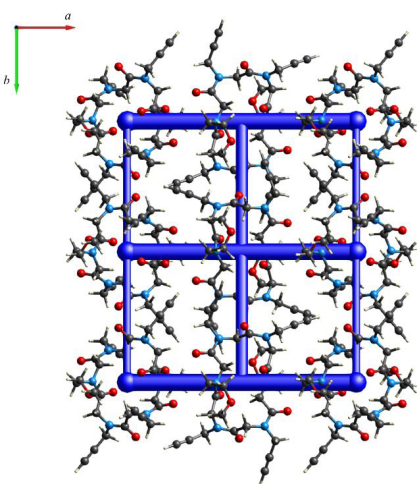

$\pi^{1 \mathrm{~B}}$

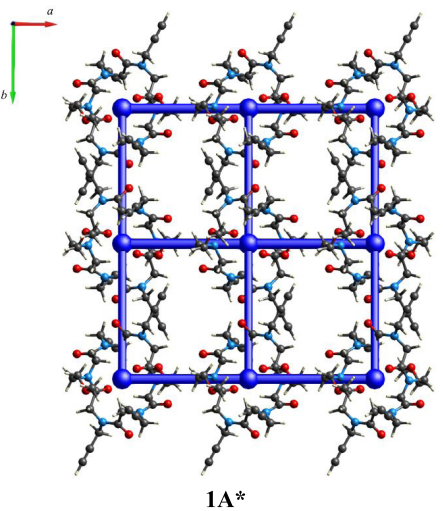

Figure 10. Energy frameworks as viewed along the $c$-axis for the host framework in $\mathbf{1 A}, \mathbf{1 B}$, and virtually empty form $\mathbf{1 A}^{*}$ (which does not correspond to a real intermediate). Cylinder radius is set to 80 ; interaction energies with magnitudes smaller than $-10 \mathrm{~kJ} \mathrm{~mol}^{-1}$ have been omitted.

1) are substituted by stronger interactions between type I and type II molecules (Motif 5 I-II; Table 2).

Energy framework analysis helped to rationalize the changes in the unit cell volumes and lattice constants due to the SCSC transformation from $\mathbf{1 A}$ to $\mathbf{1 B}$.

Upon acetonitrile release, the crystal shrinks and the unit cell volume reduces by $11.6 \%$, the $a$ - and $b$-axis decrease, respectively, by 8.5 and $3.1 \%$, while the $c$-axis remains unchanged $(\Delta c=-0.33 \%) .{ }^{49}$ The evident anisotropic decrease may be explained on the basis of the crystal packing and energy framework analysis. During the transformation from $\mathbf{1 A}$ to $\mathbf{1 B}$ :

- The columnar arrangement of the macrocycles along the $c$-axis is preserved both in $\mathbf{1 A}$ and $\mathbf{1 B}$.

- Half molecules of 1A adopt an extended conformation with all propargyl side chains in the macrocycle plane (type II molecules), in particular, the vertical propargyl chains in $\mathbf{1 A}$ rotate by $113^{\circ}$ and become horizontal to form a $\mathrm{CH}-\pi$ zipper in the $b c$-plane. 
Table 3. Packing Coefficients and Lattice Energies of 1A, 1B, and the Virtually Empty Form 1A* as Calculated by PIXEL

\begin{tabular}{lccccc} 
& packing coeff. & $E_{\text {Coul }}\left(\mathrm{kJ} \mathrm{mol}^{-1}\right)$ & $E_{\mathrm{Pol}}\left(\mathrm{kJ} \mathrm{mol}^{-1}\right)$ & $E_{\text {Disp }}\left(\mathrm{kJ} \mathrm{mol}^{-1}\right)$ & $E_{\mathrm{Rep}}\left(\mathrm{kJ} \mathrm{mol}^{-1}\right)$ \\
1A & 0.715 & -102.3 & -40.0 & -144.9 & 146.4 \\
1A* & 0.661 & -158.9 & -67.8 & -226.1 & -141.4 \\
1B & 0.748 & -172.8 & -66.5 & -256.7 & -218.0 \\
\hline
\end{tabular}

- The conformational change from type I to type II makes possible the linkage of type I and type II molecules along the $a$-axis through backbone-to-backbone $\mathrm{CH}$... OC interactions (Motif 5 I-II; Table 3 and Figure 7), which tighten the framework along the $a$-axis. Indeed, the crystal packing is more efficient in $\mathbf{1 B}$ than in $\mathbf{1 A}$, as in the former case, the packing coefficient is 0.75 and in the latter is 0.71 (Table 3).

Periodic HF-3c Calculations. To investigate the SCSC transformation, a set of HF- $3 \mathrm{c}-\left(0.27 \mathrm{~s}_{8}\right)$ periodic calculations ${ }^{38}$ was carried out using a development version of the software Crystal14. ${ }^{36,37}$ Full optimization of the studied crystal forms was performed at $\Gamma$ point.

The results of optimization were evaluated by overlapping the optimized structures with the structures obtained via SCXRD (Figure S3 in the Supporting Information) and comparing the unit cell values (Table S3 in the Supporting Information).

The direct comparison between the energies of $\mathbf{1 A}$ and $\mathbf{1 B}$ crystal structures is hampered by the different chemical contents of the two crystal structures. Indeed, to evaluate the energy change from 1A to 1B (eq 1), we need to take into account the change in the unit cell content, as the energy values are given in $\mathrm{kJ} / \mathrm{mol}$. In form 1A, there are two cyclopeptoid molecules and four acetonitrile molecules per unit cell; in form 1B, there are four cyclopeptoid molecules per unit cell (two independent molecules in the asymmetric unit). Thus, it is necessary to halve the energy value corresponding to form $\mathbf{1 B}$ and consider the energy of acetonitrile molecules in the gas phase.

The transformation from $\mathbf{1 A}$ to $\mathbf{1 B}$ is an endothermic process, as reported in eq 1

$$
\Delta E=\left[\left(\frac{E_{1 \mathrm{~B}}}{2}\right)+\left(4 \cdot E_{\mathrm{CH}_{3} \mathrm{CN}}\right)\right]-E_{1 \mathrm{~A}}=193.9 \mathrm{~kJ} / \mathrm{mol}
$$

To evaluate separately the energetic contribution of the conformational change vs the removal of acetonitrile molecules, we devised a "virtual" two-stage process:

- at first, the acetonitrile molecules leave and create a "virtually" empty crystal form 1A*, which does not correspond to a real intermediate. The event is a nonfavored process, eq 2

$$
\Delta E_{1}=\left[\left(4 \cdot E_{\mathrm{CH}_{3} \mathrm{CN}}\right)+E_{1 \mathrm{~A}}{ }^{*}\right]-E_{1 \mathrm{~A}}=218.8 \mathrm{~kJ} / \mathrm{mol}
$$

- then, half macrocycles change conformation to give crystal form 1B, eq 3 and Figures 3 and 10

$$
\Delta E_{2}=\left[\left(\frac{E_{1 \mathrm{~B}}}{2}\right)-E_{1 \mathrm{~A}} *\right]=-24.9 \mathrm{~kJ} / \mathrm{mol}
$$

Thus, a small thermal input may easily overcome the energy barrier between the two crystal forms and induce the SCSC transformation; on the other hand, the presence of acetonitrile molecules may reverse the transformation mechanism.
Upon adsorption, acetonitrile molecules bind to peptoid recognition sites, as the methylene hydrogen atoms of the methoxyethyl side chains (Motif 4-s; Table 2) and carbonyl atoms $\mathrm{O} 3$ and $\mathrm{O} 2$ (Motif 5-s; Table 2), which in $\mathbf{1 B}$ are involved in type II-type II interactions (Motif 3 II-II; Table 3) and type I-type II interactions (Motif 5 I-II; Table 3). This triggers the cooperative movement that enables the conformational change of type II molecules into type I molecules and therefore the transformation to crystal form 1A. Acetonitrile binding energies (which sum to $-38 \mathrm{~kJ} / \mathrm{mol}$ ) are enough to overcome the unfavorable energy barrier from $\mathbf{1 B}$ to $\mathbf{1 A}^{*}(+24 \mathrm{~kJ} / \mathrm{mol})$.

\section{CONCLUSIONS}

The reversible SCSC transformation of form $\mathbf{1 A}$ to $\mathbf{1 B}$ is supported by the conformational change of the cyclic peptoid molecules. Both backbone conformational change and propargyl side-chain rotation by $113^{\circ}$ make possible the formation of stabilizing (although weak) interactions as $\mathrm{CH} \cdots \mathrm{OC}$ and $\mathrm{CH}-\pi$ bonds.

Finally, the ability of flexible organic materials to adapt to external stimuli represents an opportunity for their possible future use as biomimetic sensors and/or actuators for biomedical applications.

\section{ASSOCIATED CONTENT}

\section{SI Supporting Information}

The Supporting Information is available free of charge at https://pubs.acs.org/doi/10.1021/acs.cgd.0c01244.

Structural and computational details (PDF)

Motion pictures (MP4)

\section{AUTHOR INFORMATION}

\section{Corresponding Author}

Consiglia Tedesco - Department of Chemistry and Biology "A. Zambelli", University of Salerno, 84084 Fisciano, SA, Italy; ○ orcid.org/0000-0001-6849-798X; Email: ctedesco@ unisa.it

\section{Authors}

Giovanni Pierri - Department of Chemistry and Biology "A. Zambelli", University of Salerno, 84084 Fisciano, SA, Italy; ○ orcid.org/0000-0001-5433-6077

Marta Corno - Department of Chemistry and NIS (Nanostructured Interfaces and Surfaces) Center, University of Turin, 10125 Turin, Italy; $\odot$ orcid.org/0000-0001-72482705

Eleonora Macedi - Department of Pure and Applied Science, University of Urbino "Carlo Bo", 61029 Urbino, Italy; ○ orcid.org/0000-0003-0251-901X

Maria Voccia - Department of Chemistry and Biology "A. Zambelli", University of Salerno, 84084 Fisciano, SA, Italy

Complete contact information is available at: https://pubs.acs.org/10.1021/acs.cgd.0c01244 


\section{Author Contributions}

The manuscript was written through contributions of all authors. All authors have given approval to the final version of the manuscript.

\section{Funding}

The research leading to these results received funding from the People Programme (Marie Curie Actions) of the European Union Seventh Framework Programme FP7/2007-2013 under REA grant agreement number PIRSES-GA-2012-319011.

\section{Notes}

The authors declare no competing financial interest.

\section{ACKNOWLEDGMENTS}

The authors like to acknowledge Prof. Piero Ugliengo (University of Torino), Prof. Francesco De Riccardis (University of Salerno), and Prof. Irene Izzo (University of Salerno) for valuable discussion and the University of Salerno for financial support (FARB).

\section{REFERENCES}

(1) Erbas-Cakmak, S.; Leigh, D. A.; McTernan, C. T.; Nussbaumer, A. L. Artificial Molecular Machines. Chem. Rev. 2015, 115, 10081-10206.

(2) Braga, D.; Grepioni, F. Making Crystals by Design: Methods. In Techniques and Applications; Wiley-VCH Verlag GmbH \& Co: KGaA: Weinheim, 2007.

(3) Browne, W. R.; Feringa, B. L. Making Molecular Machines work. Nat. Nanotechnol. 2006, 1, 25-35.

(4) Gangloff, N.; Ulbricht, J.; Lorson, T.; Schlaad, H.; Luxenhofer, R. Peptoids and Polypeptoids at the Frontier of Supra- and Macromolecular Engineering. Chem. Rev. 2016, 116, 1753-1802.

(5) Sun, J.; Zuckermann, R. N. Peptoid Polymers: A Highly Designable Bioinspired Material. ACS Nano 2013, 7, 4715-4732.

(6) Chongsiriwatana, N. P.; Patch, J. A.; Czyzewski, A. M.; Dohm, M. T.; Ivankin, A.; Gidalevitz, D.; Zuckermann, R. N.; Barron, A. E. Peptoids that mimic the structure, function, and mechanism of helical antimicrobial peptides. Proc. Natl. Acad. Sci. U.S.A. 2008, 105, 27942799.

(7) Comegna, D.; Benincasa, M.; Gennaro, R.; Izzo, I.; De Riccardis, F. Design, Synthesis and Antimicrobial Properties of Non-Hemolytic Cationic Alpha-Cyclopeptoids. Bioorg. Med. Chem. 2010, 18, 20102018.

(8) Howard, E.; Cousido-Siah, A.; Lepage, M. L.; Schneider, J. P.; Bodlenner, A.; Mitschler, A.; Meli, A.; Izzo, I.; Alvarez, H. A.; Podjarny, A.; Compain, P. Structural Basis of Outstanding Multivalent Effects in Jack Bean $\alpha$-Mannosidase Inhibition. Angew. Chem., Int. Ed. 2018, 57, 8002-8006.

(9) Schettini, R.; Costabile, C.; Della Sala, G.; Buirey, J.; Tosolini, M.; Tecilla, P.; Vaccaro, M. C.; Bruno, I.; De Riccardis, F.; Izzo, I. Tuning the biomimetic performances of 4-hydroxyproline-containing cyclic peptoids. Org. Biomol. Chem. 2018, 16, 6708-6717.

(10) D’Amato, A.; Volpe, R.; Vaccaro, M. C.; Terracciano, S.; Bruno, I.; Tosolini, M.; Tedesco, C.; Pierri, G.; Tecilla, P.; Costabile, C.; Della Sala, G.; Izzo, I.; De Riccardis, F. Cyclic Peptoids as Mycotoxin Mimics: An Exploration of Their Structural and Biological Properties. J. Org. Chem. 2017, 82, 8848-8863.

(11) Schettini, R.; De Riccardis, F.; Della Sala, G.; Izzo, I. Enantioselective Alkylation of Amino Acid Derivatives Promoted by Cyclic Peptoids under Phase-Transfer Conditions. J. Org. Chem. 2016, 81, 2494-2505.

(12) D’Amato, A.; Schettini, R.; Della Sala, G.; Costabile, C.; Tedesco, C.; Izzo, I.; De Riccardis, F. Conformational Isomerism in Cyclic Peptoids and Its Specification. Org. Biomol. Chem. 2017, 15, 99329942.

(13) D’Amato, A.; Pierri, G.; Costabile, C.; Della Sala, G.; Tedesco, C.; Izzo, I.; De Riccardis, F. Cyclic Peptoids as Topological Templates:
Synthesis via Central to Conformational Chirality Induction. Org. Lett. 2018, 20, 640-643.

(14) Zuckermann, R. N. Peptoid origins. Biopolymers 2011, 96, 545555.

(15) Zuckermann, R. N.; Kerr, J. M.; Kent, S. B. H.; Moos, W. H. Efficient method for the preparation of peptoids [oligo(N-substituted glycines)] by submonomer solid-phase synthesis. J. Am. Chem. Soc. 1992, 114, 10646-10647.

(16) Tedesco, C.; Erra, L.; Izzo, I.; De Riccardis, F. Solid state assembly of cyclic $\alpha$-peptoids. CrystEngComm 2014, 16, 3667-3687.

(17) Greer, D. R.; Stolberg, M. A.; Kundu, J.; Spencer, R. K.; Pascal, T.; Prendergast, D.; Balsara, N. P.; Zuckermann, R. N. Universal Relationship between Molecular Structure and Crystal Structure in Peptoid Polymers and Prevalence of the cis Backbone Conformation. J. Am. Chem. Soc. 2018, 140, 827-833.

(18) Meli, A.; Macedi, E.; De Riccardis, F.; Smith, V. J.; Barbour, L. J.; Izzo, I.; Tedesco, C. Solid-state conformational flexibility at work: zipping and unzipping within a cyclic peptoid single crystal. Angew. Chem., Int. Ed. 2016, 55, 4679-4682.

(19) Macedi, E.; Meli, A.; De Riccardis, F.; Rossi, P.; Smith, V. J.; Barbour, L. J.; Izzo, I.; Tedesco, C. Molecular recognition and solvatomorphism of a cyclic peptoid: formation of a stable $1 \mathrm{D}$ porous framework. CrystEngComm 2017, 19, 4704-4708.

(20) Pierri, G.; Landi, A.; Macedi, E.; Izzo, I.; De Riccardis, F.; Dinnebier, R. E.; Tedesco, C. Propyne gas adsorption in a cyclic hexapeptoid. A combined in-situ XRPD and DFTB study. Chem. - Eur. J. 2020, 26, 14320-14323.

(21) Allen, F. H.; Watson, D. G.; Brammer, L.; Orpen, A. G.; Taylor, R. Typical interatomic distances: organic compounds. In International Tables for Crystallography Vol. C: Mathematical. In Physical and Chemical Tables, 3rd ed.; Prince, E., Ed.; Kluwer Academic: Dordrecht, The Netherlands, 2004; pp 790-811.

(22) Frisch, M. J.; Trucks, G. W.; Schlegel, H. B.; Scuseria, G. E.; Robb, M. A.; Cheeseman, J. R.; Scalmani, G.; Barone, V.; Mennucci, B.; Petersson, G. A.; Nakatsuji, H.; Caricato, M.; Li, X.; Hratchian, H. P.; Izmaylov, A. F.; Bloino, J.; Zheng, G.; Sonnenberg, J. L.; Hada, M.; Ehara, M.; Toyota, K.; Fukuda, R.; Hasegawa, J.; Ishida, M.; Nakajima, T.; Honda, Y.; Kitao, O.; Nakai, H.; Vreven, T.; Montgomery, J. A., Jr.; Peralta, J. E.; Ogliaro, F.; Bearpark, M.; Heyd, J. J.; Brothers, E.; Kudin, K. N.; Staroverov, V. N.; Keith, T.; Kobayashi, R.; Normand, J.; Raghavachari, K.; Rendell, A.; Burant, J. C.; Iyengar, S. S.; Tomasi, J.; Cossi, M.; Rega, N.; Millam, J. M.; Klene, M.; Knox, J. E.; Cross, J. B.; Bakken, V.; Adamo, C.; Jaramillo, J.; Gomperts, R.; Stratmann, R. E.; Yazyev, O.; Austin, A. J.; Cammi, R.; Pomelli, C.; Ochterski, J. W.; Martin, R. L.; Morokuma, K.; Zakrzewski, V. G.; Voth, G. A.; Salvador, P.; Dannenberg, J. J.; Dapprich, S.; Daniels, A. D.; Farkas, O.; Foresman, J. B.; Ortiz, J. V.; Cioslowski, J.; Fox, D. J. Gaussian 09; Gaussian, Inc.: Wallingford, CT, 2009.

(23) Grimme, S. Semiempirical GGA-type density functional constructed with a long-range dispersion correction. J. Comput. Chem. 2006, 27, 1787-1799.

(24) Grimme, S.; Antony, J.; Ehrlich, S.; Krieg, H. A consistent and accurate $a b$ initio parametrization of density functional dispersion correction (DFT-D) for the 94 elements H-Pu. J. Chem. Phys. 2010, 132, No. 154104.

(25) Macrae, C. F.; Sovago, I.; Cottrell, S. J.; Galek, P. T. A.; McCabe, P.; Pidcock, E.; Platings, M.; Shields, G. P.; Stevens, J. S.; Towler, M.; Wood, P. A. Mercury 4.0: from visualization to analysis, design and prediction. J. Appl. Crystallogr. 2020, 53, 226-235.

(26) Spackman, M. A.; Jayatilaka, D. Hirshfeld surface analysis. CrystEngComm 2009, 11, 19-32.

(27) McKinnon, J. J.; Jayatilaka, D.; Spackman, M. A. Towards quantitative analysis of intermolecular interactions with Hirshfeld surfaces. Chem. Commun. 2007, 3814-3816.

(28) McKinnon, J. J.; Spackman, M. A.; Mitchell, A. S. Novel tools for visualizing and exploring intermolecular interactions in molecular crystals. Acta Crystallogr., Sect. B: Struct. Sci. 2004, 60, 627-668.

(29) Spackman, M. A.; McKinnon, J. J. Fingerprinting intermolecular interactions in molecular crystals. CrystEngComm 2002, 4, 378-392. 
(30) Turner, M. J.; McKinnon, J. J.; Wolff, S. K.; Grimwood, D. J.; Spackman, P. R.; Jayatilaka, D.; Spackman, M. A. CrystalExplorer17; University of Western Australia, 2017.

(31) Turner, M. J.; Grabowsky, S.; Jayatilaka, D.; Spackman, M. A. Accurate and Efficient Model Energies for Exploring Intermolecular Interactions in Molecular Crystals. J. Phys. Chem. Lett. 2014, 5, 42494255.

(32) Turner, M. J.; Thomas, S. P.; Shi, M. W.; Jayatilaka, D.; Spackman, M. A. Energy frameworks: insights into interaction anisotropy and the mechanical properties of molecular crystals. Chem. Commun. 2015, 3735-3738.

(33) Gavezzotti, A. Efficient computer modelling of organic materials. The atom-atom, Coulomb-London-Pauli (AA-CLP) model for intermolecular electrostatic-polarization, dispersion and repulsion energies. New J. Chem. 2011, 35, 1360-1368.

(34) Gavezzotti, A. Calculation of Intermolecular Interaction Energies by Direct Numerical Integration over Electron Densities. 2. An Improved Polarization Model and the Evaluation of Dispersion and Repulsion Energies. J. Phys. Chem. B 2003, 107, 2344-2353.

(35) Gavezzotti, A. Calculation of Intermolecular Interaction Energies by Direct Numerical Integration over Electron Densities. I. Electrostatic and Polarization Energies in Molecular Crystals. J. Phys. Chem. B 2002, 106, 4145-4154.

(36) Dovesi, R.; Orlando, R.; Erba, A.; Zicovich-Wilson, C. M.; Civalleri, B.; Casassa, S.; Maschio, L.; Ferrabone, M.; De La Pierre, M.; D’Arco, P.; Noël, Y.; Causà, M.; Rérat, M.; Kirtman, B. CRYSTAL14: A program for the $\mathrm{ab}$ initio investigation of crystalline solids. Int. J. Quantum Chem. 2014, 114, 1287-1317.

(37) Dovesi, R.; Saunders, V. R.; Roetti, C.; Orlando, R.; ZicovichWilson, C. M.; Pascale, F.; Civalleri, B.; Doll, K.; Harrison, N. M.; Bush, I. J.; D'Arco, P.; Llunell, M.; Causà, M.; Noël, Y. CRYSTAL14 User's Manual; University of Torino, 2014.

(38) Brandenburg, J. G.; Grimme, S. Dispersion corrected HartreeFock and density functional theory for organic crystal structure prediction. Prediction and Calculation of Crystal Structures; Topics in Current Chemistry; Springer: Cham, 2013; 345, 1-23.

(39) Cutini, M.; Civalleri, B.; Corno, M.; Orlando, R.; Brandenburg, J. G.; Maschio, L.; Ugliengo, P. Assessment of different quantum mechanical methods for the prediction of structure and cohesive energy of molecular crystals. J. Chem. Theory Comput. 2016, 12, 33403352 .

(40) Tatewaki, H.; Huzinaga, S. J. A systematic preparation of new contracted Gaussian-type orbital sets. III. Second-row atoms from Li through Ne. J. Comput. Chem. 1980, 1, 205-228.

(41) Broyden, C. G. The Convergence of a Class of Double-rank Minimization Algorithms 1. General Considerations. IMA J. Appl. Math. 1970, 6, 76-90.

(42) Fletcher, R. A. A new approach to variable metric algorithms. Comput. J. 1970, 13, 317-322.

(43) Shanno, D. F.; Kettler, P. C. Optimal Conditioning of QuasiNewton Methods. Math. Comput. 1970, 24, 657-664.

(44) Shin, S. B. Y.; Yoo, B.; Todaro, L. J.; Kirshenbaum, K. Cyclic Peptoids. J. Am. Chem. Soc. 2007, 129, 3218-3225.

(45) Newberry, R. W.; Raines, R. T. The $\mathrm{n} \rightarrow \pi^{*}$ Interaction. Acc. Chem. Res. 2017, 50, 1838-1846.

(46) Rahim, A.; Saha, P.; Jha, K. K.; Sukumar, N.; Sarma, B. K. Reciprocal carbonyl-carbonyl interactions in small molecules and proteins. Nat. Commun. 2017, 8, No. 78.

(47) Stringer, J. R.; Crapster, J. A.; Guzei, I. A.; Blackwell, H. E. Extraordinary Robust polyproline type I peptoid helices generated via the incorporation of $\alpha$-chiral aromatic N-1-naphthylethyl side chains. J. Am. Chem. Soc. 2011, 133, 15559-15567.

(48) Tedesco, C.; Meli, A.; Macedi, E.; Iuliano, V.; Ricciardulli, A. G.; De Riccardis, F.; Vaughan, G. B. M.; Smith, V. J.; Barbour, L. J.; Izzo, I. Ring Size Effect on the Solid State Assembly of Propargyl Substituted Hexa- and Octacyclic Peptoids. Cryst. Eng. Commun. 2016, 18, 88388848.

(49) Crystal data for 1A and 1B: 1A monoclinic, $P 2_{1} / c, a=9.773(5)$ $\AA, b=20.961(10) \AA, c=8.500(4) \AA, \beta=90.990(7)^{\circ}, V=1740.9(14)$
$\AA^{3}, Z=2, D_{\mathrm{X}}=1.322 \mathrm{~g} \mathrm{~cm}^{-3}, 1 \mathrm{~B}$ monoclinic, $P 2_{1} / c, a=17.887(3) \AA, b=$ 20.335(3) $\AA, c=8.4716(12) \AA, \beta=93.160(2)^{\circ}, V=3076.7(8) \AA^{3}, Z=$ $4, D_{\mathrm{X}}=1.318 \mathrm{~g} \mathrm{~cm}^{-3}$. To properly compare the lattice constants and the unit cell volume in $\mathbf{1 A}$ and $\mathbf{1 B}$, the crystallographic $a$ axis and the unit cell volume in form 1A must be doubled. Thus: $\Delta a \%=100\left(a_{1 \mathrm{~B}}-2\right.$. $\left.a_{1 \mathrm{~A}}\right) / 2 \cdot a_{1 \mathrm{~A}}=-8.5 \%, \Delta b \%=-3.1 \%, \Delta c \%=-0.3 \%, \Delta \beta \%=2.4 \%, \Delta V \%$ $=-11.6 \%$. 